\title{
L2 Perception of English Vowels: testing the validity of Kuhl's Prototypes
}

\section{Ma Luisa García Lecumberri \& Jasone Cenoz Iragui Universidad del País Vasco}

\begin{abstract}
The present study investigates confusion patterns in the identification of English vowel sounds by native Spanish learners. The aim was to test the validity of Kuhl's Native Language Magnet (NLM) theory for Spanish learners with an intermediate level of competence in English. Following this theory, the English and Spanish vowel systems were compared in order to obtain a set of L2 confusion predictions that could be derived from the NLM model. It was hypothesized that the prototype model would fail to account for all the confusion patterns in our data since our subjects interlanguage phonological system was no longer a direct reflection of their L1 system. A test was conducted in which subjects were asked to identify RP vowels in monosyllabic words after receiving specific phonetic training. It was observed that few perceptual confusions could be explained according to the NLM model as interpreted for L2 acquisition. We propose that the NLM theory can only account for L2 data if revisions are made as to the nature of prototypes in the interlanguage. The NLM model should also take into account other factors that may shape prototypes such as vowel duration and universals principles.
\end{abstract}

\section{Introduction}

In the study of second language (L2) acquisition much has been said about learners' errors. Traditional contrastive analyses saw transfer from native language (NL) as the main reason 
for these errors (Stockwell and Bowen 1965). More recently, various studies have made a point of minimizing the importance of transfer and have ascribed errors to developmental or intralingual processes amongst other reasons (Richards 1971; Dulay and Burt 1973). Notwithstanding the importance of interlanguage (IL) processes and performance errors, it is nevertheless true that most authors (Scholes 1968, Wode 1980; Altemberg and Vago 1983; Ioup 1984; Ellis 1985, 1994, Flege et al. 1994) believe that phonetic/phonological mistakes are very often due to first language $(\mathrm{L} 1)$ influences. In this sense, sound system differences between the NL and the target language (TL) may pose various degrees of difficulty to learners which, at a perceptual level, will be manifested as confusions. This is not to say that language differences lead to errors, but that they may do so. The effect of language interference is mediated by other constraints such as markedness (Eckman 1977), universal tendencies (Altemberg et al. 1983) learners' L2 proficiency and specific training (Cenoz and García $1995 \mathrm{a}$ and $b$ ). For instance, when the NL makes one distinction where the TL has two different sounds, it is likely that beginner learners will confuse the two TL units favouring the one closest to their native category. However, at a later stage of L2 knowledge learners may present more intralingual errors (Major 1987).

Perceptual confusions have been a particular object of phonetic research as far as infants' developing sound systems are concerned (Kuhl 1993; Werker and Polka 1993). Kuhl explains confusions in the discrimination of new sounds in terms of prototypes. This theory, properly know as the Native Language Magnet (NLM) (Kuhl 1993, 1995, Iverson and Kuhl 1995, 1996) proposes that listeners' perceptual sound systems are composed of best exemplars for each sound category. These best exemplar or prototype "perceptually assimilates surrounding stimuli to a greater extent than is the case for a non-prototype" (Kuhl 1993, 127). That is to say, prototypes act like magnets with respect to other sounds so that sensitivity to sound differences is reduced in their proximity whereas it is increased in the proximity of non-prototypes. Thus sounds which resemble a best exemplar are difficult to differenciate from it because the prototype attracts to itself perceptions of sounds that fall under its scope the way a magnet would.

Kuhl's theory of prototypes was first described with reference to infants' perceptions (Kuhl 1991) but even then some reference was made to its possible application to second language acquisition by stating that linguistic experience affects prototype constitution in the sense that the magnet effect in infants is only exhibited by native language sounds. Later on, the applicability of NLM theory to L2 acquisition was made more explicit:

The NLM theory also helps explain the results of studies on adults' perception of sounds from a foreign language. (...) I would suggest that foreign contrasts are difficult to discriminate when the prototype of a native-language category closely resembles both foreign-language sounds. (Kuhl 1993, 131)

It is clear from the above quotation that according to the NLM model, L1 sounds act as prototypes (magnets) in L2 acquisition. This is very much in keeping with theories who propose that the L1 sound system acts as a "grid" through which L2 sounds are perceived (Wode 1981). 
In this paper we intend to explore the validity of Kuhl's prototype model in the perception of English vowels by Spanish learners. Our hypothesis is that the model, as it stands, will not account satisfactorily for identifications by listeners with an intermediate competence in English because their developing interlanguage sound system differs both from the phonological system of their NL and from that of the TL.

Before testing NLM theory, let us make explicit some of its more important ideas and their implications for L2 acquisition. We shall separate them in three points for ease of reference.

A- "Foreign language units that are similar to a native-language category are particularly difficult to perceive as different from the native-language sound" (...) "the nearer a new sound is to a native language magnet, the more it will be assimilated by it, making the new sound indistinguishable from the native language sound"(Kuhl 1993, 131) This would imply that L2 sounds which most closely resemble L1 sounds would be interpreted as prototypes (or "prototype-like" in our terms). It would then be expected that prototype-like sounds should have the highest number of right identifications.

B- "exposure to a primary language distorts the underlying perceptual space by reducing sensitivity near phonetic prototypes (...) adults learning a second language would find it difficult to perceive a phonetic contrast from a new language when the sounds are proximate to a native language prototype"(Iverson and Kuhl 1995, 561) This would imply that a new sound which resembles a prototype would be perceptually attracted to it whereas nonprototypes would not attract other sounds. Additionally, a non prototype-like sound is easier to differenciate perceptually than a sound which resembles a prototype.

C- (...) "foreign contrasts are difficult to discriminate when the prototype of a nativelanguage category closely resembles both foreign language sounds ${ }^{1}(. .$.$) the difficulty in$ discriminating two foreign-language sounds depends on their proximity to a native language magnet. The nearer they are, the more difficult to discriminate" (Kuhl 1993, 131). This would imply that when two sounds are very similar to a single prototype, there should be mutual perceptual confusions.

To test the validity of the above claims in a L2 situation, a perception test was conducted. Its design and results will be presented in the following section.

\section{Test procedure and results}

\subsection{Materials}

A test was designed in which Spanish learners of English were asked to identify English vowel sounds. A tape was elaborated consisting of 38 stimulus words spoken by a male RP speaker. For the purposes of the present study ${ }^{2}$, only 22 words will be taken into account (see Appendix 1). Each word was a monosyllable containing one of the 11 vowels being tested. The 11 vowels included all RP simple vowels except for schwa. Schwa was not included because it cannot occur in a monosyllable in citation form.

Each vowel was present in two different words. The words were taken from Roach (1991). Vowel length was taken into account in the sense that all vowels were presented 
followed by voiceless sounds so that all of them would undergo pre-fortis clipping (Wells 1990). This was done in order to avoid extrinsic vowel length being used as a distinctive parameter. Each stimulus was presented twice.

This test was presented to all the students who registered for Phonetics of English in the academic year 1994-95 before and after receiving specific phonetic training. A discussion of vowel perceptions before training can be found in García and Cenoz 1995. In this paper we shall discuss the results obtained after training (see also Cenoz and García 1995 b). Subjects were first year students of English Philology at the University of the Basque Country The original number of subjects who took the test was 181 . The study concentrates on 117 subjects, the rest having been disregarded because they failed to answer to all the stimuli, they chose more than one alternative in their answers or because they otherwise invalidated their answer sheets.

\subsection{Procedures}

The test was a semi-open one: for each item a list of all 19 phonetic symbols was presented so that listeners had the whole range of vowels to choose from (except schwa). Consequently, the test was almost totally open but guided. Phonetic symbols were used so as to minimize the effect of spelling influences. At the time listeners took the test they were familiar with the symbols since they had been doing phonetics for four months.

Answer papers included a paragraph with some explanations on the procedure of the test. Instructions referred to the lay-out of the answer sheets and the tape. Subjects were asked to choose only one alternative per stimulus. They were also encouraged not to leave any blanks. Students were reassured that the results of the test would have no bearing on their academic results and were informed that the test was simply trying to monitor their ability to recognize English vowels. The test took place in a language laboratory with subjects listening through headphones.

\subsection{Results}

Frequencies and percentages were calculated for answers to each stimulus using the SPSS program. Mean percentages were obtained for responses to the two instances of each vowel. Values were subsequently laid out in the confusion matrix below (Klein et al. 1970). 


\begin{tabular}{|c|c|c|c|c|c|c|c|c|c|c|c|}
\hline & $\mathrm{i}:$ & I & $\mathrm{e}$ & $æ$ & $\Lambda$ & a: & $\mathrm{D}$ & 3: & 0 & $\mathrm{u}:$ & 3: \\
\hline $\mathrm{i}:$ & 47.9 & 51.7 & & & & & & & & & \\
\hline I & 8.1 & 86.8 & 4.7 & & & & & & & & 0.5 \\
\hline $\mathrm{e}$ & & 1.3 & 92.3 & 3.5 & & & & & & & 2.6 \\
\hline $\mathfrak{x}$ & & & & 81.7 & 15.0 & 3.4 & & & & & \\
\hline$\Lambda$ & & 0.5 & & 15.8 & 81.6 & 0.9 & & & & & \\
\hline $\mathrm{a}:$ & & & & 3.4 & 3.9 & 92.3 & & & & & 0.5 \\
\hline$D$ & & & & 0.9 & 3.4 & 12.8 & 53.9 & 29.1 & & & \\
\hline $0:$ & & & & & & & 12.4 & 85.1 & & 0.5 & \\
\hline$\delta$ & & & & & 1.3 & & & & 82.5 & 16.25 & \\
\hline $\mathrm{u}:$ & & & & & & & & & 35.9 & 63.7 & \\
\hline 3: & & & 3.4 & 9.6 & 5.7 & 9.5 & 3.9 & 2.6 & & & 62.5 \\
\hline
\end{tabular}

Table 1. Confusion Matrix in the identification of RP vowels by Spanish university students. Values are given in mean percentages.

The above table reflects the means of two responses per vowel in percentages. It is organized as follows: the vertical axis corresponds to the stimulus vowels presented to listeners; the horizontal axis represents the vowel symbols chosen by the subjects. Figures in bold correspond to correct vowel identifications. In the table, diphthongs have been excluded from the response (horizontal) axis. This was done because there were very few monophthongs that were interpreted as diphthongs, and in no case was the mean percentage of diphthong response significant. The highest diphthong choice was $/ e \partial /=2.2 \%$ for the stimulus /3:/. This value will be taken into account when discussing /3:/ perceptions.

It is readily apparent that no vowel showed really poor identifications, the worst results (vowel /i:/) are only just below 50\% correct interpretations. There are four vowels whose identification rates fall around the $50 \%$ zone: $/ \mathrm{i}: /, / \mathrm{D} /, / 3: /, / \mathrm{u}: /$. All other vowel stimuli show correct identifications above $80 \%$.

\section{Discussion}

This section will be divided in three parts. First we shall explore acoustic relationships between the English monophthongs under study and the five Spanish monophthongs. Based on these relationships, we will propose which of the English vowels can be seen as prototypelike by Spanish learners. Secondly, and taking into account the relationships established in part 2, we will hypothesise on NLM's predictions, as outlined in the introduction above, for Spanish perceptions of English vowels. Finally we shall examine in what sense and to what extent these predictions are born out by our data. 


\subsection{Acoustic relationships between English and Spanish vowels}

The acoustic values used for establishing relationships between the Spanish and the English (RP) simple vowel systems correspond to male productions of each set of vowels. For the five Spanish monophthongs acoustic values (see Appendix 2) are taken from Quilis and Esgueva (1983). From their data, means were calculated for the first and second formants from the mean values given by the authors for the seven Spanish males in their corpus. Formant values correspond to stressed realizations of the Spanish vowels. The acoustic values used for English (see appendix 1) are taken from Wells 1962 (reprinted in Fry 1979). These values correspond to two stressed tokens of each vowel as produced by 25 English males, all of which were RP speakers.

To make the following description more reader-friendly, we will not mention specific formant values for vowels (please refer to appendix 2 for details). For the same reasons, Spanish vowel symbols will be noted in italics and plain font, English symbols in plain type and IPA font.

Following the proposal (see above) that native-language sounds act as magnets, we will use the term "prototype" for L1 sounds, and the term "prototype-like" for L2 sounds which may be perceived as equivalent or near equivalent to the $L 1$ sounds.

English/i:/. The English vowel is quite similar to Spanish/i/one so we could assume that /i:/ would be thought of as prototype-like

English /D/ . Its F1 is between the values for two prototypes, /i/ and /e/, though F2 is nearer to $/ e /$, so there is a greater correspondence with/e/but not to the extent that the English vowel would be regarded as prototype-like.

English /e/. The English vowel is between /e/ and /a/ for F1 but much nearer /e/ for F2. Additionally, because $\mathrm{F} 2$ for the English sound is so far from $/ a /$, it is quite likely that English /e/ might be equated with the Spanish prototype/e/.

English /æ/. This vowel is nearest to /a/ in F1 and nearest to /e/ in F2. The F1 distance between $/ æ /$ and $/ a /$ is smaller than the one between $/ æ /$ and $/ /$ in $\mathrm{F} 2$ so that the English vowel is more similar to Spanish $/ a /$. Nevertheless, it might be said that $/ \mathfrak{a} /$ falls between prototypes.

English $/ N$. The nearest Spanish vowel is $/ a /$ but it is further from it than the following sound in our discussion (/a: $/$ ). Therefore, it seems unlikely that $/ N$ will be thought of as prototypelike; rather it might be perceived as a non-prototypical (non-exemplar)/a/sound.

English/a:/. The English vowel is very close to the Spanish prototype/a/with respect to both formants. In fact, this is the closest relationship between vowels in the two languages. It is thus very likely that it will be considered prototype-like. 
English /D/. The English sound's F1 is like /a/ but its F2 is similar to / $/$. Both distances between the English and Spanish formants are nearly equal. However, /o/s F1 dissimilarity from $/ \mathrm{p} / \mathrm{sF} 1$ is less than $/ \mathrm{a} / \mathrm{s} \mathrm{F} 2$ dissimilarity to $/ \mathrm{D} / \mathrm{sF} 2$ so that the English sound is more like $/ o /$. Nevertheless we can safely assume that $/ \mathrm{D} /$ is between prototypes.

English $/ \mathrm{o} /$. Its $\mathrm{F} 1$ is like the one for $/ \mathrm{o} / \mathrm{but} \mathrm{F} 2$ is between the ones for $/ \mathrm{o} / \mathrm{and} / \mathrm{u} /$. Thus, there is a greater correspondence with $/ o /$ but not to the extent that the English vowel would be regarded as prototype-like.

English $/ \sigma /$. Its F1 is between $/ o /$ and $/ u /$ but F2 is nearer the one for Spanish $/ o /$ so, again, greater correspondence with $/ o /$ but not likely to be interpreted as prototype-like.

/u:/ vs. Spanish /o/ and / $/$ / Its F1 is like / $/$ but F2, like above, is more like /o/ There is a stronger correspondence with $/ u$ / because the F1 similarity is greater than the other, F2, correspondence.

English /3:/ There is no one correspondence with Spanish vowel values. Its F1 is like /e//o/ and $/ a /$ (nearest to $/ a /$ ) and its F 2 is nearest to $/ a /$ too but not very much so (fronter by $230 \mathrm{~Hz}$ ).

\subsection{NLM implications for the data}

From the above; we can see there are five different situations for which we shall try to obtain perceptual predictions following the NLM theory ${ }^{3}$ :

(1) Only /i:/ and /a:/, are likely to be regarded as prototype-like (strong prototypes or good exemplars). Following the interpretation of NLM theory outlined above, these two sounds would present the highest number of right identifications and should also attract perceptions of non prototypical acoustically similar sounds such as $/ \mathrm{I} /$ and $/ \mathrm{N}$ respectively.

(2) An English sound (/u:/) resembles two native prototypes (/u/ and $/ \mathrm{o} /$ ), although it is more similar to one of them(/u:/ $>/ u /)$, and no other English sound resembles the native prototype so closely This situation is not made explicit by Kuhl, but we could expect the English sound to act as a prototype since there is no other English sound competing for that role within that prototype category, although with less force (weak prototype or poor exemplar) and more confusions than the sounds in (1) above. There could also be confusions with the English vowel which most closely resembles the other prototype $(/ \mathrm{o} />/ \mathrm{0} /)$

(3) Some English sounds share values almost equally with two native sounds in that F1 is like one Spanish sound and F2 is like another sound. In those cases, the foreign sounds fall between prototypes and would not be regarded as prototypes themselves $\left(/ æ /^{4}, / \mathrm{D} /\right)$. In those instances, we suppose NLM theory should predict equal confusions with the native prototypes due to competing magnet forces. In our test, it would be expected that the two English sounds which most resemble the two native prototypes would be chosen: $/ æ />/ \mathrm{e} /$ and $/ \mathrm{a}: / ; / \mathrm{D} />/ \mathrm{a}: /$ and $/ \mathrm{o}: /$. Additionally these two sounds, being non-prototypical, should not attract other vowel perceptions. 
(4) There are also cases in which two English sounds resemble one native prototype (see $\mathrm{C}$ above) $/ \mathrm{I} /$ and $/ \mathrm{e} />/ e /, / 0: /$ and $/ \sigma />/ \% /$. As was pointed out above, we should expect a considerable number of mutual confusions between each pair. Additionally, the one nearest to the native prototype (in bold) should be favoured. All these English sounds also resemble another native prototype, although less strongly. This would be a further source of perceptual confusions:/1/ $>/ \mathrm{i}: / ; / \mathrm{e} />/ \mathrm{a}: / ; / 0: /$ and $/ \mathrm{J} / \mathrm{>} / \mathrm{u}: /$.

(5) Finally there is one vowel, /3:/, for which only one formant, F2, is anything like any one native sound, namely la/ (but still not too much so) whereas the other formant, F1, is between three native sounds $(/ e /, / a /$ and $/ o /)$, so we must say that this sound really does not resemble any one prototype closely. The NLM model would predict, on the one hand, no confusions with prototypes or prototype like sounds. If there is a bias, it should be towards la/ (and therefore /a:/) since it is the least different vowel. On the other hand (see B above), we should also expect this vowel to be very distinctive as far as perception is concerned.

\subsection{NLM theory versus results}

In this section we shall report the instances in which NLM predictions, as outlined in section 3.2 above, successfully and unsuccessfully account for the data. For clarity purposes we shall follow the same order and categories as in the previous section.

(1)

/i: / = This sound, closely resembling the native prototype, should have had a very high number of right identifications. This is not born out by our data. The number or correct perceptions is quite low, in fact it is the lowest one in the test. It should also have exerted a magnet effect towards acoustically neighbouring sounds such as/I/. Actually, our data show the opposite outcome:/I/ has a very high number of correct identifications and, moreover, it attracts /i:/ to a very large extent (over $50 \%$ of perceptions) whereas the prototype-like sound (/i:/) is only the second choice.

/a: / = This vowel does behave as a prototype in as much as it shows a very high number of correct identifications (over $92 \%$ ). As for attracting neighbouring sounds, the results are contradictory. We had predicted $/ N$, being the nearest vowel, to be identified as/a:/. However it is $/ æ /$ which attracts $/ N$, which in turn has a very high number of correct identifications. On the other hand, the prototypical sound /a:/ exerts a magnet force over $/ 0 /$ and $/ 3: /$ Consequently, we may conclude that the NLM model works for /a:/, although predictions as to which sounds would be attracted are not supported by the data. It may be the case that the phonetic realizations of the sounds involved, because of the speaker or the phonetic context, were different to the values followed in this study.

(2)

$\mathrm{u}: /=$ Again we find a case of a near prototype which does not behave as such. It exhibits a moderate rate of correct identifications (63\%) and, though it does attract a neighbouring sound $(/ \sigma /)$, it is itself attracted by that same vowel to a much larger extent. This result mirrors the one found with the high front vowels above (/i:/ and/I/): a non-prototype exerts a strong 
magnet force over a prototype-like vowel. On the other hand, predicted confusions with $/ 0: /$ are not found in our data.

/æ/versus $/ \mathrm{e} /$ and $/ \mathrm{a}: /=$ As a non prototype vowel, it was predicted that $/ æ /$ would be confused with the two nearest prototype like sounds, /e/ and /a:/. Table 1 above shows no confusions with /e/ and only a few with /a:/. Therefore, /æ/ shows confusions in only one direction and displays no evidence of competing magnet effects. In fact, once more we find that a non prototype exerts the strongest attraction, namely $/ N$. It might be supposed that, actually, the latter sound is the one closest to the native category /a/. However, as we saw before, /a:/ displays a considerably better rate of correct identifications than $/ N$. This fact, together with the formant similarities observed in 3.1, would lead us to persist in considering/a:/ as more prototypical. Finally, the high percentage of correct identifications for $/ \mathfrak{a} /$ belie its classification as a non-prototype.

/D/ versus /a:/ and / $/ /$. In this case NLM predictions are substantiated by our data. There seems to be considerable competition between /a:/ and / $/:$ as magnets, although there is a noticeable bias towards the latter vowel. It is also the case that $/ \mathrm{D} /$ does not behave as a prototype in as much as correct perceptions are concerned (only 53\%).

(4)

$/ \mathrm{I} /$ and $/ \mathrm{e} /=$ We saw above that the magnet relationship between $/ \mathrm{I} /$ and $/ \mathrm{i}: /$ was reversed. We had also predicted confusions between $/ \mathrm{I} /$ and the other neighbouring vowel, /e/, with bias towards the latter because it resembles the native prototype more closely. As can be observed in table 1 above, the data confirm our hypotheses to different degrees. There are confusions between the two sounds but only a few. This is not surprising considering the very good identification rates that both vowels display, particularly /e/. Therefore, /e/ is regularly identified with the native prototype, but when it is not, choices favour the non prototypical vowel/æ/instead of /a:/.

/ $: /$ and $/ \mho /$ Both vowels display very high rates of right perceptions (over $80 \%$ ). However, against predictions, there are no mutual confusions. In the instances where $10: /$ was misidentified, the non-prototype sound $/ \mathrm{D} /$ was chosen nearly always. The amount of identifications with its other neighbouring vowel, /u:/, are negligible $(0.5 \%)$. In the case of wrong identifications for $/ \mho /$, our predictions are confirmed, since $/ u$ :/ is favoured. We can see that $/ 0: /$ and $/ \mathrm{J} /$ do not follow Kuhl's hypothesis as outlined in section 1 above. These are two vowels that closely resemble a native prototype and should, therefore, be difficult to tell apart. This is not the case in our data since there are no confusions with each other but with third sounds. 
/3:/ = It was pointed out above that this is the English vowel that least resembles any of the native categories. Accordingly, it should not be confused with prototypes and it should be highly distinctive. In our data, the most apparent thing is the dispersion of perceptions: there are seven different sound choices ${ }^{5}$ to the stimulus $/ 3: \%$. The moderately high $(62 \%)$ number of correct identifications together with the dispersion just mentioned, may be indicators that this vowel is indeed perceived as distinct to all the others. In this sense, dispersion of wrong identifications would be due to the fact that no single vowel exerts a strong magnet influence over $/ 3: /$. It was also predicted above that confusions might favour / $\mathrm{a}: /$ since the corresponding native vowel /a/ is the least different to /3:/ acoustically. Nevertheless, although /a:/ is chosen more often than most other sounds, it competes with /æ/, a non protoypical sound. In this respect we cannot posit clear NLM influences which is what the theory anticipated for this sound.

\section{Conclusions}

The above results show that the NLM model does not account for most of the confusion patterns found in our data. There are but few instances that follow our NLM based predictions (see above discussion for $/ \mathrm{a}: /$ and $/ \mathrm{D} /$ ).

There are several reasons why Kuhl's model may have failed to account for our data. Some of them may be related to the nature of the test reported in this paper, since subjects were not being asked to identify L2 stimuli with L1 categories, the magnet effect was being analyzed in a tangential manner. It could also be the case that our interpretation of NLM model may have been at fault. Additionally, the phonetic context in which stimulus vowels were presented may have influenced their realization and perception (Strange et al. 1979, Gottfried and Strange 1980)

On the other hand, we believe that, although the NLM model offers interesting ideas for the interpretation of L2 acquisition of vowels, it should also contemplate several other factors that may influence the magnet potential of a prototype. First of all, for non beginner L2 learners, prototypes should be defined taking into account their interlanguage phonological system(Eckman 1981b, Ellis 1985, 1993, Gass and Selinker 1994). This system is shaped by various factors other than the learners' native language system, such as markedness or universal principles (Eckman 1977, 1981a, Altemberg and Vago 1983, Major 1987). Finally, the NLM theory explicitly works with formant frequencies to depict the acoustic space of vowels. Certainly, it has often been shown that formants provide good characterizations of vowels (Peterson and Barney 1952, Fairbanks and Grubb 1961) and that the distance between formants depicts the auditory differences between vowel sounds (Flege et al. 1994, amongst others). Nevertheless, vowel length has also been claimed as a very important factor in vowel perception (Strange et al. 1979, Hillenbrand et al. 1995, Fox et al 1995). We believe that many of the confusion patterns observed in our data may be related to vowel duration. Even though, as we mentioned above, we tried to avoid duration differences caused by consonant contexts, vowel duration may have been an important factor. Intrinsic vowel duration may have been used as a parameter in addition to formant values. It could also be the case that students ordinarily expect long vowels to show considerable duration in all contexts, not 
being familiar with pre-fortis clipping. Therefore, they may have been misled by the shortened stimuli in the test. In our experience, this last hypothesis seems very likely.

We must conclude that, although the NLM model did not account for the perceptual results in our data, more tests isolating several variables must be conducted before determining the viability of the model (see also Sussman and Lauckner-Morano 1995). Nevertheless, it seems already apparent that, as far as L2 acquisition is concerned, the NLM theory needs to incorporate various changes; most importantly, an adequate characterization of prototypes in interlanguage phonological systems. In this sense we agree with Lacerda (1995) in that "the very nature of the language acquisition process requires prototypes that can be rearranged in the perceptual space"( 141). That is to say, considering that during L2 acquisition the interlanguage is a dynamic changing entity, unless fossilization has set in, the study of prototypes should take into account the nature of the developing sound system at each particular stage.

\section{Acknowledgments}

This research was supported by the Universidad del País Vasco grant 103.130-HA136/94.

Appendix 1: Stimulus words

1./bi:f/, 2./bi:t/

3. /mIs/, 4. /bIt/

$5 . / \mathrm{mes} /, 6 . /$ bet/

7./pæt/, 8./gæp/

9. $/ \mathrm{k} \wedge \mathrm{t} / 10 . / \mathrm{k} \wedge \mathrm{p} /$

11./pa:k/, 12./ha:f/

13./pDt/, 14./los/

$15 . / \mathrm{fo}: \mathrm{t}, 16 . / \mathrm{ko}: \mathrm{s} /$

17./pひt/, 18./pひs/

19./ru:f/, 20./lu:k/

21./h3:t/,22./d3:t/

Appendix 2: Formant values

\begin{tabular}{llllll}
\multicolumn{2}{l}{ Spanish $\mathrm{i}$} & $\mathrm{e}$ & $\mathrm{a}$ & $\mathrm{o}$ & $\mathrm{u}$ \\
& & & & & \\
$\mathrm{F}_{1}$ & 270 & 420 & 640 & 460 & 270 \\
$\mathrm{~F}_{2}$ & 2350 & 2010 & 1150 & 840 & 680
\end{tabular}

First and second formant values for Castillian Spanish vowels. Obtained from values presented by Quilis and Esgueva (1983) for 6 male speakers in accented syllables

\begin{tabular}{||l|l|l|l|l|l|l|l|l|l|l|l||}
\hline Engl. & i: & I & e & a & $\wedge$ & a: & D & O: & U & u: & 3: \\
\hline$F_{1}$ & 300 & 360 & 570 & 750 & 720 & 680 & 600 & 450 & 380 & 300 & 580 \\
\hline$F_{2}$ & 2300 & 2100 & 1970 & 1750 & 1240 & 1100 & 900 & 740 & 950 & 940 & 1380 \\
\hline
\end{tabular}


Wells' (1962) first and second formant values for RP English vowels obtained from 9 male speakers in accented syllables. Reproduced in Fry (1979).

\section{Notes}

1. Part of the first quotation is repeated here for reasons of convenience.

2. Originally, target vowels included 11 monophthongs and 8 diphthongs, which accounts for there being 38 stimuli words. In this paper we shall concentrate on monophthong perceptions.

3. It should be born in mind that in our test, listeners were not given the option of choosing a native language sound. We were interested in discovering the prototypification of English sounds in students' interlanguages. Therefore, we shall be looking at the reflection of magnet effects on their choice of English vowels.

4. Flege (1991) describes /æ/ as being majoritarily identified with Spanish/a/. However, in his experiment neither/a:/ nor / $N$ were being used as competing stimuli.

5. As was indicated in 2.3 . above, we will take into account the fact that $/ 3: /$ showed a $2.2 \%$ rate of confusions with the diphthong /eə/.

\section{Works cited}

Altemberg, E. P. and Vago, R. M.: "Theoretical Implications of an Error Analysis of Second Language Phonology Production", Language Learning, 33 (1983):, 427-447.

Cenoz Iragui, J, and García Lecumberri, M.L., "The Acquisition of Phonetics: Factors Affecting the Discrimination of English Vowels," Actas Del Xix Congreso Deaedean (1995): 189-193.

Cenoz Iragui, J. and García Lecumberri, M. L., "The Effect of Training On the Discrimination of English Vowels," International Review of Applied Linguistics, (1995) (In Press).

Dulay, H. and Burt, M. "Should We Teach Children Syntax?." Language Learning, 23 (1973): 24558.

Eckman, F. R., "Markedness and the Contrastive Analysis Hypothesis." Language Learning, 27 (1997): 315-330.

Eckman, F. R. "On Predicting Phonological Difficulty in Second Language Acquisition." Studies in Second Language Acquisition, 4 (1981): 18-30.

Eckman, F. R., 1981b, On the Naturalness of Interlanguage Phonological Rules." Language Learning, 31 (1981): 195-216.

Ellis, R. Understanding Second Language Acquisition. Oxford: O.u.p, 1985.

Ellis, R.,.The Study of Second Language Acquisition. Oxford: O.u.p, 1994.

Fairbanks, G. and Grubb,P.,"A Psychophysical Investigation of Vowel Formants" Journal of Speech and Hearing Research, 4 (1961): 203-219.

Flege, J. E.."The Interlingual Identification of Spanish and English Vowels: Orthographic Evidence." Quarterly Journal of Experimental Psychology, 43 (1991): 701-731.

Flege, J. E., Munro, M. J. and Fox, R. A. "Auditory and Categorical Effects On Cross-language Vowel Perception." Journal of the Acoustic Society of America, 95 (1994): 3623-3641.

Fox, R. A., Flege, J.E. and Munro M. J.. "The Perception of English and Spanish Vowels By Native English and Spanish Listeners: A Multidimensional Scaling Analysis." Journal of the Acoustic Society of America, 97 (1995): 2540-2551. 
Fry, D. B. the Physics of Speech. Cambridge: Cup, 1979.

Gass, S M. and Selinker, L. Second Language Acquisition, New Jersey: Lawrence Erlbaum, 1994.

García Lecumberri, M. L. and Cenoz Iragui, J., "Perception of Rp Vowels By Spanish Speaking University Students." Actas Del Xix Congreso Deaedean (1995): 299-304.

Gottfried T. L. and Strange, W. "Identification of Coarticulated Vowels."Journal of the Acoustic Society of America, 68 (1980): 1626-1635.

Hillenbrand, J., Getty, L. A., Clark, M. J. and Wheeler, K., 1995. "Acoustic Characteristics of American English Vowels.", Journal of the Acoustic Society of America, 97 (1995): 3099-3111. Ioup, G., " Is There a Structural Foreign Accent? A Comparison of Syntactic and Phonological Errors in Second Language Acquisition." Language Learning, 34 (1984): 1-17.

Iverson, P. and Kuhl, P. K. "Mapping the Perceptual Magnet Effect For Speech Using Signal Detection Theory and Multidimensional Scaling." Journal of the Acoustic Society of America, 97 (1995): 553-562.

Iverson, P. and Kuhl, P. K. "Influences of Phonetic Identification and Category Goodness On American Listeners' Perception of /R/ and/L/." Journal of the Acoustic Society of America, 99 (1996): 1130-1140.

Klein W., Plomp P. and Pols L. "Vowel Spectra, Vowel Spaces and Vowel Identification." Journal of the Acoustic Society of America, 48 (1970): 999-1009.

Kuhl, P. K. "Human Adults and Human Infants Show a 'Perceptual Magnet Effect'for the Prototypes of Speech Categories, Monkeys Do Not." Perception and Psychophysics, 50(1991): 93-107.

Kuhl, P. K. "Early Linguistic Experience and Phonetic Perception: Implications For Theories of Developmental Speech Production." Journal of Phonetics, 21 (1993): 125-139.

Kuhl, P. K. "Mechanisms of Developmental Change in Speech and Language." Proceedings of the International Congress of Phonetic Sciences, Stockholm, 1995.

Lacerda, F., "The Perceptual Magnet Effect: An Emergent Consequence of Exemplar-based Phonetic Memory." Proceedings of the International Congress of Phonetic Sciences, Stockholm, 2(1995): 140-147.

Major, R. C., "Phonological Similarity, Markedness, and Rate of L2 Acquisition." Studies in Second Language Acquisition, 9 (1987): 63-82.

Peterson, G. E. and Barney, H. L. "Control Methods Used in a Study of Vowels." Journal of the Acoustic Society of America, 24 (1952): 175-184.

Quilis, A. and Esgueva, M. "Realización De Los Fonemas Vocálicos Españoles En Posición Fonética Normal." Estudios De Fonética 1, (M. Esgueva and M. Cantarero, Editors), Madrid: C.s.i.c, 1983, 159-252.

Richards, J."A Non Contrastive Approach ToError Analysis." English Language Teaching Journal, 25 (1971): 204-219.

Roach, P. 1991, English Phonetics and Phonology, (1983 1st Edition). Cambridge: C.u.p, 1991.

Scholes, R. J. "Phonemic Interference As a Perceptual Phenomenon." Language and Speech, 11 (1968): 86-103.

Stockwell, R. P. and Bowen, J. D. the Sounds of English and Spanish. Chicago: University of Chicago Press, 1965.

Strange, W., Edman, T. R. and Jenkins, J. J. "Acoustic and Phonological Factors in Vowel Identification." Journal of Experimental Psychology, Human Perception and Performance, 5 (1979): 643-656. 
Sussman, Je and Lauckner-morano, V. J. " Further Tests of the 'Perceptual Magnet Effect' in the Perception of/L/: Identification and Change/no-change Discrimination." Journal of the Acoustic Society of America, 97 (1995): 539-552.

Wells, J.C., A Study of Formants of the Pure Vowels of British English, M.A. Thesis (Unpublished), University of London, 1962.

Wells, J. C. Longman Pronunciation Dictionary. Harlow: Longman, 1990.

Werker, F. J. and Polka, L. "Developmental Changes in Speech Perception: New Challenges and New Directions.." Journal of Phonetics, 21 (1993): 83-101.

Wode, H. "Phonology in L2 Acquisition." Second Language Development, (S.W. Felix, Editor), Tübingen: Gunter Narr, 1981. 123-138. 